\title{
Orgasm-induced seizures
}

INSERM

\section{Source}

INSERM. (1999). Orphanet: an online rare disease and orphan drug data base. Orgasminduced seizures. ORPHA:166421

Orgasm-induced seizures is a rare neurologic disease characterized by complex partial seizures with or without secondary generalization, or idiopathic primarily generalized epilepsy, triggered by sexual orgasm. Seizures usually start immediately, shortly after or a few hours after the achievement of orgasm, last a few seconds or minutes, and are followed, in very rare cases, by intense migraine. 